\title{
natureouTLOoK EPILEPSY
}

10 July 2014 / Vol 511 / Issue No 7508

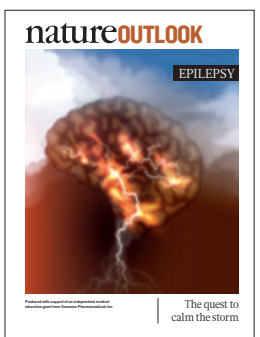

Cover art: Nik Spencer

\section{Editorial}

Herb Brody,

Mike May,

Michelle Grayson,

Kathryn Miller

Nick Haines

Art \& Design

Mohamed Ashour,

Alisdair Macdonald,

Andrea Duffy

Production

Donald McDonald,

Susan Gray, lan Pope

Christopher Clough

Sponsorship

Will Piper,

Yvette Smith,

Samantha Morley

Marketing

Steven Hurst,

Hannah Phipps

Project Manager

Anastasia Panoutsou

Art Director

Kelly Buckheit Krause

Publisher

Richard Hughes

Magazine Editor

Rosie Mestel

Editor-in-Chief

Philip Campbell
$\mathrm{E}$ pilepsy has been documented for thousands of years and can affect anyone at any age. There are at least a dozen types of epilepsy - the exact number depends on who is being asked - that can start in and spread to different brain regions, creating a range of seizure types. The World Health Organization conservatively estimates that 50 million people worldwide have epilepsy; yet, despite its prevalence, the condition attracts relatively little research funding (page S2).

Part of the reason for the dearth of treatments is the long history of social stigma and fear that once surrounded people with the condition (page S10). Perhaps the most complex piece of the epilepsy puzzle is the fact that we still don't understand the brain itself; simply knowing some of the roles of neurotransmitters and ion channels does not explain why some people develop epilepsy (page S4). Studies have helped us understand enough of epilepsy's neurobiology to use surgery as a treatment, which is why neurologist Samuel Wiebe proposes that this tool is used more widely (page S7).

Neuroscience and genetics have exposed crucial pieces of the epilepsy process, but studies have not determined the network of genes that drive seizures (page S8). Until recently even drug-makers tackled epilepsy by trial and error, but now researchers are using new targets and drug development strategies to help create more effective medicines (page S12). A high-fat, low-carbohydrate diet can help reduce seizure frequency in young children (page S14), and in the future, sensors that can be worn to predict an oncoming seizure could have clinical and research applications (page S16).

This Outlook was produced with the support of an independent medical education grant from Sunovion Pharmaceuticals Inc. As always, Nature Publishing Group retains sole responsibility for all editorial content.

\section{Mike May}

Contributing Editor
Nature Outlooks are sponsored supplements that aim to stimulate interest and debate around a subject of interest to the sponsor, while satisfying the editorial values of Nature and our readers' expectations. The boundaries of sponsor involvement are clearly delineated in the Nature Outlook Editorial guidelines available at go.nature.com/e4dwzw

CITING THE OUTLOOK

Cite as a supplement to Nature, for example, Nature Vol. XXX, No. XXXX Suppl., Sxx-Sxx (2014).

VISIT THE OUTLOOK ONLINE

The Nature Outlook Epilepsy supplement can be found at

http://www.nature.com/nature/outlook/epilepsy

It features all newly commissioned content as well as a selection

of relevant previously published material.
All featured articles will be freely available for 6 months. SUBSCRIPTIONS AND CUSTOMER SERVICES For UK/Europe (excluding Japan): Nature Publishing Group, Subscriptions, Brunel Road, Basingstoke, Hants, RG21 6XS, UK. Tel: +44 (0) 1256329242. Subscriptions and customer services for Americas - including Canada, Latin America and the Caribbean: Nature Publishing Group, 75 Varick St, 9th floor, New York, NY 10013-1917, USA. Tel: +1 8663637860 (US/Canada) or +1 212726 9223 (outside US/Canada). Japan/China/Korea: Nature Publishing Group - Asia-Pacific, Chiyoda Building 5-6th Floor, 2-37 Ichigaya Tamachi, Shinjuku-ku, Tokyo, 162-0843, Japan. Tel: +81 332678751. CUSTOMER SERVICES

Feedback@nature.com

Copyright $\odot 2014$ Nature Publishing Group

\section{CONTENTS}

S2 EPIDEMIOLOGY

The complexities of epilepsy

Charting a century of research

S4 NEUROBIOLOGY

Unrestrained excitement

Understanding the mechanisms

behind seizures

S7 PERSPECTIVE

The surgical solution

Samuel Wiebe argues the case for surgery as an epilepsy treatment

S8 GENETICS

Complex expressions

Possible genes involved in epilepsy

S10 SOCIOLOGY

Shedding the shame

The social stigma of epilepsy

S12 DRUG DEVELOPMENT

Illuminated targets

The quest for new treatments

S14 FOOD SCIENCE

Fat chance

Inhibiting seizures with a high-fat diet

S16 TECHNOLOGY

Dressed to detect

Wearable epilepsy sensors could

help to save lives

\section{COLLECTION}

S18 Mutations of DEPDC5 cause autosomal dominant focal epilepsies S. Ishida et al.

S22 GABA progenitors grafted into the adult epileptic brain control seizures and abnormal behavior R. F. Hunt et al.

S28 Brain mitochondrial metabolic dysfunction and glutamate level reduction in the pilocarpine model of temporal lobe epilepsy in mice O. B. Smeland et al.

S36 De novo mutations in epileptic encephalopathies

Epi4K Consortium \& Epilepsy Phenome/ Genome Project

\$41 The pathology of magneticresonance-imaging-negative epilepsy Z. I. Wang et al. 